\title{
UPPER GI BLEEDING: CAUSES, MORBIDITY AND MORTALITY IN ADMITTED PATIENTS AT TERTIARY CARE HOSPITAL OF KARACHI.
}

\footnotetext{
1. MBBS FCPS

Assistant Professor

Department of Medicine Unit 4

Civil Hospital Karachi.

2. MBBS FCPS

Professor

Department of Medicine

Civil Hospital Karachi.

3. MBBS

House Physician

Civil Hospital Karachi.

4. Final Year MBBS Student

Dow Medical College.

5. MBBS

House Physician

Civil Hospital Karachi.

6. MBBS, FCPS

Professor

Department of Medicine

DIMC, Dow University Hospital Karachi.

7. MBBS, FCPS

Associate Professor Department of Medicine

Rawal Medical College Rawal Pindi.

8. MBBS FCPS

Associate Professor

Department of Medicine

Dow Medical College, Civil Hospital Karachi.
}

Correspondence Address:

Dr. Naresh Kumar Seetlani

Flat No. 301, Block A

Clifton View Apartment Near Teen

Talwar, Clifton Karachi.

drnaresh2004@yahoo.com

Article received on:

06/02/2019

Accepted for publication:

25/04/2019

\section{ABBREVIATIONS}

UGIB: Upper gastrointestinal bleeding, NSAIDS: Non-steroidal anti-inflammatory drugs, AVH: Acute variceal haemorrhage, NVUGIH: Nonvariceal upper gastro-intestinal haemorrhage, Hep B: Hepatitis B, HCV: Hepatitis C virus, DM: Diabetes Mellitus, HTN: Hypertension, SRH: Stigmata of recent hemorrhage, CHK: Civil Hospital Karachi.

\section{INTRODUCTION}

Upper gastrointestinal bleeding/haemorrhage (UGIB/UGIH) has been the most frequently
Naresh Kumar Seetlani ${ }^{1}$, Khalid Imran ${ }^{2}$, Pooja Deepak ${ }^{3}$, Fizza Tariq ${ }^{4}$, Daniyal Mirza ${ }^{5}$, Amanullah Abbasi ${ }^{6}$, Nadia Shams ${ }^{7}$, Tehseen Akhtar ${ }^{8}$

STRACT... Objectives: Acute upper gastrointestinal bleed is one of the most common (he medical field, gastrointestinal bleeding still carries significant mortality and fiscal burden on healthcare system. At present, limited data is available on the predictors of morbidity and mortality associated with acute upper gastrointestinal leeding in our part of the country. Study Design: Descriptive analytical study. Setting: wards of Civil Hospital Karachi. Period: From January 2018 to June 2018. Materia and Methods: 260 patients of 12 years and above with complaint of upper gastrointestinal bleeding. After hemodynamic stabilization, patients were referred to undergo esophago-gastroduodenoscopy at the endoscopy suite of the hospital. Their personal data and endoscopic findings were recorded after obtaining a written consent. The patients were followed for 2 weeks to document the factors leading to their morbidity and mortality. We used Rockall scoring system to identify risk of patient mortality. Data collected was analyzed using SPSS 22.0. Results: The survey included 260 patients having males (62.3\%) more than females (37.7\%) with age ranging from 12 to 85 years. Among all, variceal bleed was accounted in 186 (71.5\%) patients while remaining 74 (28.4\%) patients had non-variceal bleed; peptic ulcer disease being the most common etiology. The overall mortality rate of our study was $5 \cdot 76 \%$. Some factors influencing mortality of the patients were age $>60$ years, comorbid, use of NSAIDS, rebleeding, deranged laboratory tests at the time of presentation- anemia (hemoglobin of $<10 \mathrm{~g} \backslash \mathrm{dl}$ ), grade 3 thrombocytopenia (platelet count of $<50$ cells $\backslash$ dl), serum creatinine $>1.5$ and serum INR of $>$ 1.6. Additionally, a direct proportion was seen in between Rockall scoring system and patient mortality with a significant p-value (0.000). Conclusion: In this study, variceal bleeding was found as the predominant lesion of upper gastro-intestinal bleeding followed by peptic ulcer disease. Certain factors are found that are strongly related in deteriorating patient's outcome. Along with it, Rockall score is also a good predictor of outcome of patients.

Key words: $\quad$ Esophago-gastro-Duodenoscopy, Morbidity, Mortality, Non-variceal Bleed, Rebleeding, Upper Gastrointestinal Bleed, Variceal Bleed.

Article Citation: Seetlani NK, Imran K, Deepak P, Tariq F, Mirza D, Abbasi A, Shams N, Akhtar T. Upper GI bleeding: Causes, morbidity and mortality in admitted patients at Tertiary Care Hospital of Karachi. Professional Med J 2019; 26(11):19161924. DOI: 10.29309/TPMJ/2019.26.11.3224 which patients present to the hospital and carries a substantial patient morbidity and mortality. ${ }^{1}$ The Gl tract is divided into an upper and lower part by the presence of ligament of Treitz, a peritoneal fold suspending the duodenojejunal flexure. It thus becomes a landmark to categorize extensive GI tract. The source of UGIB lies somewhere proximal to the ligament of Treitz while that of lower Gl bleed lies distal to the ligament of Treitz. ${ }^{2}$ Though this division is not exclusive to localize the source of bleeding, but it guides from where to start investigating a patient. ${ }^{3}$ There are 
many causes of upper GI bleed; few illustrations include esophageal varices with or without portal hypertension, peptic ulcer disease, gastritis, oesophagitis, duodenitis, upper GI malignancies, Mallory-Weiss tears, angiodysplasia, uremia, haemobilia or coagulation disorders. ${ }^{4,5}$ but the two most common causes encountered in our region are bleeds due to oesophageal varices and peptic ulcer disease. ${ }^{5}$

Broadly UGIB is categorized into two main types, i.e. variceal and non-variceal bleed, both carrying different intervention and prognosis. Acutevariceal haemorrhage $(\mathrm{AVH})$ is a major complication of portal hypertension occurring in almost $30 \%$ of patients with cirrhosis and accounting for $80-90 \%$ of bleeding episodes in these patients. ${ }^{6}$ Studies highlight Hepatitis as a major culprit of cirrhosis with Hepatitis C Virus (HCV) causing 41-52\%, followed by Hepatitis B Virus (HBV) causing 30\% of the cases ${ }^{7}$ with a mortality rate of $11-50 \%{ }^{1}$ In contrast, non-variceal upper gastro-intestinal haemorrhage (NVUGIH) is most often caused by erosive gastritis and peptic ulcer disease- NSAID intake and H.Pylori infection being at the top of the causative factors of ulcer disease ${ }^{8}$ with an overall mortality rate of around 3-14\% which is far lesser than the $\mathrm{AVH}{ }^{1}$

UGIB can present in various ways. Though the most common symptoms of patients are melena, blood in vomitus either fresh (hematemesis) or altered blackish clots (coffee-ground emesis), hematochezia (fresh blood per rectum) or sometimes just land with iron-deficiency anemia having microscopic fecal bleed loss. ${ }^{5,9}$ The most appropriate step taken at that time in the management of patient is to perform an endoscopy as soon as possible which is a primary therapeutic and diagnostic modality that allows to evaluate the cause of UGIB and to control the bleed with various endoscopic measures as well. ${ }^{10}$ According to the current international guidelines, upper Gl endoscopy should be performed within 24 hours of patient presentation which appears to be more helpful in guiding further intervention and reducing the need for prolonged hospitalization. ${ }^{11}$

Endoscopy has played a very vital role in emergent management of patient. Over the last 20 years, many dramatic changes have been made in the management strategies of UGIB including the introduction of acid suppressive therapy and endoscopic haemostasis which has decreased the need for surgical interventions, but despite all those advancements, mortality rate remained relatively unchanged of about $6-13 \%$, accounted in most studies. ${ }^{12}$ Numerous studies support the fact that majority of deaths do not result from failure of medical or surgical interventions but from comorbidities, poorly tolerated severe blood loss and resultant complications of the underlying etiology. ${ }^{13}$ According to various studies, factors significantly influencing the mortality in patients presenting with UGIB were increasing age, presence of co-morbidities (diabetes mellitus, hypertension, ischemic heart disease, chronic renal failure), systolic blood pressure $<100$ $\mathrm{mm} \mathrm{Hg}$, advanced Child-Pugh score, presence of hepatic encephalopathy, hepatocellular carcinoma, hemoglobin $<10 \mathrm{~g} / \mathrm{dL}$, international normalized ratio (INR) $>1 \cdot 6$, serum creatinine $>$ $2 \cdot 0 \mathrm{mg}$ and early re-bleeding after endoscopy. ${ }^{6,7,10}$ Rebleeding, occurring in approximately 10-30\% of cases, is also considered an important hazard of uprising mortality. ${ }^{14}$

The rationale of our study is to determine the etiological patterns of UGIB and common factors involved in morbidity and mortality of the patients because this data in context of our population is important to take more careful preventive measures and improve management tactics.

\section{METHODOLOGY}

A descriptive analytical study was conducted on a total of 260 patients including both males and females from 12 to 85 years of age, presented in the Medicine department of Civil Hospital Karachi. The project continued from January 2018 to June 2018. All referred in-patients, out-patients and ones who landed in the emergency department with complaint of upper GI bleed (hematemesis, melena and hematochezia) were included in the study. The participants were followed for up to 2 weeks to evaluate the risk factors that increase the morbidity and mortality of patients. 
After initial hemodynamic stabilization of patients in the emergency department with crystalloids, blood or blood products (if necessary), intravenous proton pump inhibitors and intravenous vasoconstrictor; Octreotide (if known underlying liver pathology with high suspicions of having variceal bleed), upper Gl endoscopies were performed by experienced endoscopists in our endoscopy suite. A formal written consent was obtained from every patient for contributing in the study. Saeed's six shooter band ligator was used for esophageal varices and injection histoacryl and lipiodol were used for obliteration of fundal varices while injection diluted adrenaline 1:10000 heater probe and hemoclips were used for non-variceal bleed.

After endoscopy, patients were shifted to their primary ward for further evaluation and were discharged afterwards depending upon their vital status and well-being. Data of all participated patients were collected in a standardized and detailed way including mode of presentation, any ongoing illness (especially gastric or liver diseases), coexisting illnesses, history of previous hospital admission, drug history, thorough examination findings, baseline blood and radiological investigations, medical treatment given initially, endoscopic results, incidence of rebleeding, need for transfusion before or after endoscopy and cause of death (if occurred so). The whole multivariate analysis was then used to get Rockall score of individual patients. Rockall system is one of the several risk analysing tools used to stratify risk of mortality of patients with UGIB by classifying them into low, moderate or high-risk group. ${ }^{15}$ The parameters of Rockall scoring system include three clinical variables (age, shock, and comorbidity) and two endoscopic variables (diagnosis and major $\mathrm{SRH}$ ). It classifies patients into three categories on the basis of individual calculated score which is: score $<3$ are low risk, score of 3-4 are moderate risk and $>4$ are high risk patients. ${ }^{16}$ After calculation, an association between Rockall score and patient's outcome (morbidity and mortality) was assessed. The data collected was analysed by using SPSS version $22 \cdot 0$.

\section{Inclusion and Exclusion Criteria}

We included adult male and pregnant and nonpregnant female patients aged $\geq 12$ years who presented with upper Gl bleed either as a first episode or subsequent episodes of bleed whether recorded as a principal diagnosis at the time of admission or underwent an in-patient bleed, having any other reason of admission. Children were not included. Patients having any other source of bleeding such as from airways were excluded. Patients who did not give consent or those who were not fit for endoscopy were also excluded.

\section{RESULTS}

A total of 260 individuals were added in the survey from which 162 (62.3\%) were males and 98 $(37.7 \%)$ were females. Their age ranged between 12 to 85 years from which majority $(n=197,75 \cdot 8 \%)$ of the candidates were less than 60 years. The clinical profile of patients showed that a total of $227(87.3 \%)$ had both hematemesis and melena while remaining $33(12.7 \%)$ had non-specific symptoms (symptoms of anemia, hematochezia or fecal occult blood). Only 147 (56.5\%) patients gave a significant history of previous hospital admission with the same complain. In the study, oesophago-gastro-duodenoscopy (OGD) extracted varices (esophageal or fundal) with evident portal hypertension in 186 (71.5\%) patients as the most common lesion for bleeding. Among those 186 patients, 134 were diagnosed cases of hepatitis $\mathrm{C}$-being the most common leading cause of varices, and 35 suffered from hepatitis B. However, 13 patients had no proven history of such viral infections (sero-negative) but still had variceal bleed. On the other hand, rest of the $74(28.4 \%)$ patients had non-variceal etiology of bleed; peptic ulcer disease accounted as the most common etiology of that. (Figure-1)

The possible risk factors of non-survivors contributing in their mortality are given in Table-II.

Furthermore, in our study, a good correlation is made in between Rockall score and mortality of a patient. (Table-III) Patients were categorized into three groups following their obtained Rockall scores as, low risk (group 1) who scored from 0 
till 3, moderate risk (group 2) who scored 3-4 and high risk (group 3 ) who scored $>4$. It was seen that majority of the patients who died belonged to group 3 (high risk) with a Rockall score > 4. At significance level 95\%, the p-value for Rockall score and patient's outcome was 0.000 (or less than 0.001 according to NEJM0) which is statistically significant. Hence, the greater the Rockall score, greater would be the morbidity and mortality of a patient.
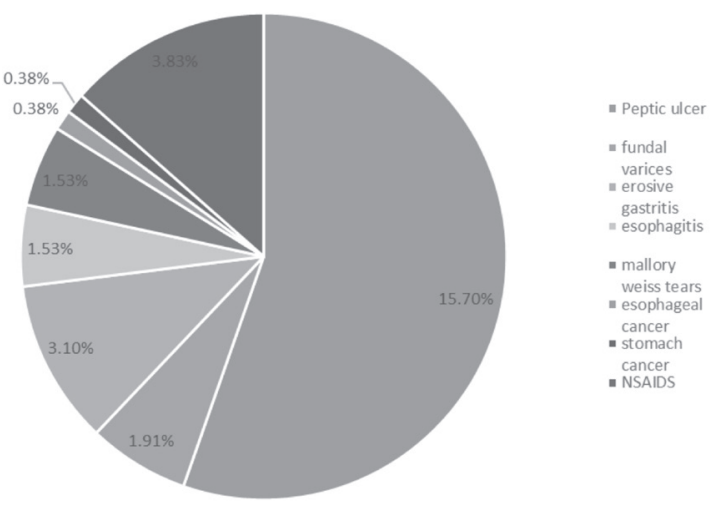

Figure-1. The pie chart shows various non-variceal etiological factors in patients with upper gastrointestinal bleed.

\begin{tabular}{|l|c|c|c|}
\hline \multicolumn{1}{|c|}{ Outcome } & $\begin{array}{c}\text { Number } \\
\text { of } \\
\text { Patients }\end{array}$ & Percentage & Mortality \\
\hline $\begin{array}{l}\text { bleeding } \\
\text { resolved in 24 } \\
\text { hrs }\end{array}$ & 206 & $79 \cdot 2$ & 3 \\
\hline $\begin{array}{l}\text { bleeding } \\
\text { resolved in } \\
\text { greater than 24 } \\
\text { hrs }\end{array}$ & 35 & $13 \cdot 5$ & 4 \\
\hline $\begin{array}{l}\text { rebleeding } \\
\text { within 24 hrs }\end{array}$ & 8 & $3 \cdot 1$ & 4 \\
\hline $\begin{array}{l}\text { rebleeding } \\
\text { greater than 24 } \\
\text { hrs }\end{array}$ & 11 & $4 \cdot 2$ & 4 \\
\hline \begin{tabular}{l} 
Total \\
\hline
\end{tabular} & 260 & $100 \cdot 0$ & 15 \\
\hline
\end{tabular}

Table-I. The bar chart below shows outcome of patients after undergoing upper GI endoscopy.

\section{DISCUSSION}

Upper gastrointestinal bleed has become a predominant reason for emergency hospital admissions worldwide. ${ }^{17}$

\begin{tabular}{|c|c|c|}
\hline Parameters & $\begin{array}{c}\text { Number of } \\
\text { Non-survivors }\end{array}$ & $\begin{array}{l}\% \text { of Non- } \\
\text { survivors }\end{array}$ \\
\hline $\begin{array}{l}\text { Age } \\
<60 \\
>60\end{array}$ & $\begin{array}{c}11 \\
4\end{array}$ & $\begin{array}{l}73 \cdot 3 \\
26 \cdot 6\end{array}$ \\
\hline $\begin{array}{l}\text { Sex } \\
\text { Males } \\
\text { Females }\end{array}$ & $\begin{array}{l}9 \\
6\end{array}$ & $\begin{array}{l}60 \\
40\end{array}$ \\
\hline $\begin{array}{l}\text { Etiology } \\
\text { Variceal bleed } \\
\text { Non-variceal bleed }\end{array}$ & $\begin{array}{c}11 \\
4\end{array}$ & $\begin{array}{l}73 \cdot 3 \\
26 \cdot 7\end{array}$ \\
\hline $\begin{array}{l}\text { Comorbids } \\
\text { Yes } \\
\text { No }\end{array}$ & $\begin{array}{l}8 \\
7\end{array}$ & $\begin{array}{l}53 \cdot 3 \\
46 \cdot 7\end{array}$ \\
\hline Hepatitis B & 3 & 20 \\
\hline Hepatitis C & 12 & 80 \\
\hline NSAID use & 5 & $33 \cdot 3$ \\
\hline $\begin{array}{l}\text { Blood transfusion } \\
\text { Pre-endoscopy } \\
\text { Post-endoscopy }\end{array}$ & $\begin{array}{c}12 \\
0\end{array}$ & 80 \\
\hline Rebleeding & 8 & $53 \cdot 33$ \\
\hline $\begin{array}{l}\text { Hemoglobin } \\
<10 \\
>10\end{array}$ & $\begin{array}{c}12 \\
3\end{array}$ & $\begin{array}{l}80 \\
20\end{array}$ \\
\hline $\begin{array}{l}\text { Platelets } \\
150-450 \text { lacs } \\
75000-150 \text { lac } \\
50000-75000 \\
25000-50000 \\
<25000\end{array}$ & $\begin{array}{l}5 \\
6 \\
2 \\
2 \\
0\end{array}$ & $\begin{array}{c}33 \cdot 3 \\
40 \\
13 \cdot 3 \\
13 \cdot 3 \\
0\end{array}$ \\
\hline $\begin{array}{l}\text { Creatinine } \\
<1.1 \\
1 \cdot 2-2 \cdot 0 \\
>2\end{array}$ & $\begin{array}{l}9 \\
4 \\
2\end{array}$ & $\begin{array}{c}60 \\
26 \cdot 7 \\
13 \cdot 3\end{array}$ \\
\hline $\begin{array}{l}\text { INR } \\
<1 \cdot 6 \\
>1 \cdot 6\end{array}$ & $\begin{array}{l}7 \\
8\end{array}$ & $\begin{array}{l}46 \cdot 7 \\
53 \cdot 3\end{array}$ \\
\hline $\begin{array}{l}\text { Systolic blood pressure } \\
<100 \mathrm{~mm} \mathrm{Hg} \\
>100 \mathrm{~mm} \mathrm{Hg}\end{array}$ & $\begin{array}{l}8 \\
7\end{array}$ & $\begin{array}{l}53 \cdot 3 \\
46 \cdot 7\end{array}$ \\
\hline $\begin{array}{l}\text { Endoscopic intervention } \\
\text { Yes } \\
\text { No }\end{array}$ & $\begin{array}{l}8 \\
7\end{array}$ & $\begin{array}{l}53 \cdot 3 \\
46 \cdot 7\end{array}$ \\
\hline $\begin{array}{l}\text { Rockall score } \\
<3 \\
3-4 \\
>4\end{array}$ & $\begin{array}{l}0 \\
6 \\
9\end{array}$ & $\begin{array}{c}0 \\
40 \\
60\end{array}$ \\
\hline
\end{tabular}




\begin{tabular}{|c|c|c|}
\hline \multicolumn{1}{|c|}{ Rockall Score } & $\begin{array}{c}\text { Number of } \\
\text { Patients }\end{array}$ & Mortality (\%) \\
\hline$<3$ (Low risk) & 47 & $0(0 \%)$ \\
\hline $1-4$ (Moderate risk) & 149 & $6(2 \cdot 3 \%)$ \\
\hline$>4$ (High risk) & 64 & $9(3 \cdot 46 \%)$ \\
\hline Total & 260 & $15(5 \cdot 76 \%)$ \\
\hline \multicolumn{2}{|r|}{ Table-III. Illustrates correlation between Rockall } \\
score and patient's mortality.
\end{tabular}

It carries a serious clinical implication for health care because of its high morbidity and mortality which has remained unchanged in years. There are several causes of UGIB, varying geographically. In Eastern part of the world, the most notable cause of UGIB is variceal bleed, a cardinal feature of portal hypertension. ${ }^{18,19}$ This might be due to rampant effects of hepatitis in our population, causing cirrhosis (Chronic liver disease) and varices. A survey of few years ago calculated the prevalence of hepatitis $B$ and $C$ in Pakistan as $2.4 \%$ and $3 \%$ respectively. ${ }^{20}$ In contrast, peptic ulcer disease- a non-variceal lesion of bleed has appeared to be the most common cause in western sides, occurring secondarily to $\mathrm{H}$.pylori infection or NSAIDS. ${ }^{17}$

According to the statistics of the United States, more than 350,000 patients get hospitalized annually with UGIB ${ }^{4}$ having mortality rates of $5 \%$ to $11 \% .{ }^{10}$ According to a research, the mortality of esophageal or fundal variceal bleed in patients with underlying cirrhosis had been reported to be as high as $50 \%{ }^{18}$ whereas mortality of non-variceal bleed had reached to $10-14 \% .{ }^{19}$ Although more recent data elucidates that use of more potent vasoactive drugs, advent of various endoscopic measures and surgical procedures have played a pivotal role in reducing mortality rates of variceal bleed to $20 \%{ }^{18}$ and of non-variceal bleed to $3 \cdot 8$ $5 \cdot 6 \%{ }^{21}$ but still they are on the higher side. Hence, the mortality of $\mathrm{Gl}$ bleeding has not decreased much during the past 50 years.

Many researches have been done to enlighten the clinical and endoscopic profile of patients suffering from UGIB, but very limited data is available to evaluate the factors associated with mortality of such patients, specifically in our region. Therefore, this study was designed to identify the most common causes leading to UGIB and illuminate some of the important factors increasing the morbidity and mortality of patients presenting to our hospital.

According to some previous researches, geriatric population has a very high incidence of UGIB with poor outcome. This could be supported by the fact that older people have more comorbid and many of them are chronic NSAIDS users, both of them predispose to bleed. ${ }^{22}$ In a study done by Mahajan et $\mathrm{al}^{23}$, a greater number of population who presented with UGIB belonged to elderly group, most of them having comorbid conditions. Similarly, in the present study, more than fifty percent of the patients were in their fifth or sixth decade having certain comorbid (diabetes mellitus, hypertension, ischemic heart disease or renal failure) which significantly increased the fraction of death.

In our study, out of 260 patients, $62 \cdot 3 \%$ were males while only $37 \cdot 7 \%$ were females who came with complain of UGIB which gives an idea that UGIB is more common in males than their counter partners. An Indian study done by Anand et al. ${ }^{10}$ also showed similarity with the current one in which the ratio of male to female bleeders was $5: 1$ with $83.3 \%$ males and $16 \cdot 6 \%$ females. Moreover, our study found hematemesis along with melena as the most common symptom of patients coming to the hospital. This finding showed dissimilarity with the work of Gregor et al. in which $60 \%$ patients of UGIB landed with only hematemesis in the hospital. ${ }^{24}$

Coming on to the cause of UGIB, a variety of etiological spectrum were encountered in different studies from various regions of world. For instance, a survey done by Lakhwani et al. concluded that the most common reason for upper Gl bleed was peptic ulcer disease due to H.pylori. ${ }^{22}$ Similarly, studies of Czernichow et al. and colleagues ${ }^{25}$ in France and by Elghuel et al. in Middle East ${ }^{26}$ also found peptic ulcer disease as the most frequent reason for UGIB followed by varices and erosive disease. In contrast, according to the result of our research, variceal bleed was found to be 
the most common pathological lesion leading to UGIB, with $54.62 \%$ of population reported to have esophageal varices with portal hypertensive gastropathy and $14.3 \%$ had fundal varices. Peptic ulcer disease which was encountered in $7 \cdot 7 \%$ of patients remained the next common cause of UGIB. This finding of ours coincided with a study done in Egypt by Elsebay et al. in which more than half of the patients were diagnosed with variceal cause of upper Gl bleed. ${ }^{27} \mathrm{~A}$ recent study in Nepal also contracted the same etiology in upper $\mathrm{Gl}$ bleeders. ${ }^{28}$ This difference in pattern might be due to a great prevalence of infectious liver diseases; like hepatitis $B$ and hepatitis C in Asian regions which are one of the common reasons of chronic liver disease leading to portal hypertension and variceal bleed. ${ }^{5}$

In terms of management of upper gastrointestinal bleeding, upper Gl endoscopy is the mainstay of treatment in active bleeders and should be done within 24 hours of presentation of patient to control the bleed and evaluate the cause. ${ }^{29}$ According to numerous researches, early endoscopic intervention significantly improves the outcome and reduces patient mortality. ${ }^{30}$ But the guidelines provided by the American Society of Gastrointestinal Endoscopy and the American College of Gastroenterology recommend that hemodynamic stabilisation of unstable patients should be prioritized over endoscopic intervention ${ }^{31}$ which is done mostly with a sufficient amount of crystalloid infusion and precise monitoring of vital signs. The same protocol was followed in the emergency department of $\mathrm{CHK}$, where patients initially underwent vital stabilization by various measures like crystalloid or blood infusion (if needed), and then were proceeded for further necessary interventions. Consecutively, pharmacotherapy with antacids (proton pump inhibitors) and vasoactive drugs (sandostatin or terlipressin) are an essential adjunct to endoscopy which reduce further episodes of rebleeding and make subsequent endoscopic intervention easy. ${ }^{30}$

Rebleeding and outcome showed a substantial correlation, with rebleeding itself being an independent prognostic factor for mortality. ${ }^{32}$
Survey done by Bambha et al. evidenced re-bleeding in 37 (15\%) out of 256 patients and showed a significant risk of mortality 6 weeks post-AVH, leaving an adverse effect on overall survival of patients. ${ }^{33}$ However, in our study, rebleeding occurred in total of 19 patients (7.3\%) with a mortality of 8 patients (3.07\%) equally belonging to variceal and non-variceal group of bleeders.

Discoursing the laboratory results of patients, it is said that presenting hemoglobin levels are proportionally related to patient's consequence. In a research work of Chaikitamnuaychok et al., an $\mathrm{Hb}$ of $<10 \mathrm{~g} / \mathrm{dL}$ and systolic blood pressure of $<100 \mathrm{mmHg}$ at presentation were considered one of the indicators of a noticeable increase in mortality. ${ }^{34}$ Similarly, in the present study, patients with $\mathrm{Hb}<10 \mathrm{~g} / \mathrm{dL}(\mathrm{n}=12)$ and those who were hypotensive at the initial occasion $(n=8)$ died more than those having normal hemoglobin or mild anemia. In correspondence to it, a disturbed INR and impaired renal function were also predictively significant. According to a study of Deep Anand et al., an international normalized ratio (INR) of $>$ $1 \cdot 6^{10}$ contained high mortality which is favoured by the results of current study in which 8 patients with disturbed INR had worse outcome than rest. Moreover, he also added that serum creatinine $>2.0 \mathrm{mg} / \mathrm{dL}^{10}$ was seen most commonly in nonsurvivors than in survivors. Though this feature contradicts with the result extracted in our study in which majority of non-survivors $(n=9)$ had creatinine in normal limits while only 2 deceased patients had serum creatinine $>2.0 \mathrm{mg} / \mathrm{dL}$ when they landed in the hospital. Nevertheless, such laboratory results are indispensable and should be put into consideration in determining risk of mortality.

The analysis of patients was done by calculating Rockall score of them. This is basically an assessment algorithm which consists of few variables including clinical criteria and endoscopy results to classify bleeders into low, moderate and high-risk categories and approximate the risks of mortality. ${ }^{16}$ It is evidenced that mortality increases in a stepwise fashion as the risk score increases. The result of our study coincides with the concept 
as majority of deaths occurred in patients who belonged to high-risk group having cumulative score of $>4$. This finding absolutely accords with the results of Phang et al. in which patient mortality was high with rockall score $>4 .{ }^{35}$

Overall mortality of our study was $5 \cdot 76 \%$ (15 out of 260 patients expired), out of which 11 (4.2\%) patients expired from variceal group of UGIB, 3 $(1 \cdot 1 \%)$ patients due to ulcer disease and 1 (0.38\%) patient with gastric malignancy which proved that varices carry higher mortality ration as compared to other non-variceal causes of bleeding.

\section{LIMITATIONS}

Several limitations are encountered in this study. Firstly, there are various scoring systems that have been used nowadays for classification and for intervention but unfortunately, the complexity of these scoring systems limits their use in routine practice. Secondly, due to the government setup and heavy patient load, we are unable to perform endoscopy within 24 hours of patient admission which is followed world-wide. That's why patients are managed initially by conservative measures and then are enlisted for endoscopy which might have taken days and even weeks from their first presentation. This hinders the accurate diagnosis most of the times and may play a role in deteriorating the underlying disease and to patient's death.

\section{RECOMMENDATIONS}

Early upper GI endoscopy (within 24 hours of presentation) is recommended in all bleeders because it confirms the diagnosis and allows for targeted endoscopic treatment, resulting in reduced morbidity and mortality. ${ }^{23}$ Rebleeding is very important and a prompt attention should be taken either endoscopically or surgically as soon as the occurrence of event. It can occur in 10 $20 \%$ of patients despite successful endoscopic therapy and endoscopy must be attempted once more in such patients. Surgical intervention may be required in patients with severe and persistent bleeding. ${ }^{23}$ Apart from that, laboratory work-up should be done in every patient coming with UGIB and values must be put into consideration as they also are profound in predicting mortality.
Hence, further intervention should be planned accordingly to correct the underlying laboratory errors.

\section{CONCLUSION}

In this study, variceal bleeding was found as the predominant lesion of upper gastro-intestinal bleeding followed by peptic ulcer disease. Certain factors are found that are strongly related in deteriorating patient's outcome. Along with it, Rockall score is also a good predictor of outcome of patients.

\section{CONFLICTS OF INTEREST}

The research project used endoscopy suite and equipment required for esophago-gastroduodenoscopy of Civil Hospital Karachi.

\section{Copyright $@ 25$ Apr, 2019.}

\section{REFRENCES}

1 Wysocki J D, Srivastav S, Winstead N S. A nationwide analysis of risk factors for mortality and time to endoscopy in upper gastrointestinal haemorrhage. Aliment Pharmacol Ther 2012; 36: 30-36.

2 Glick Y. Ligament of Treitz https://radiopaedia.org/ articles/ligament-of-treitz.(02-02-2018).

3 Strate L L. Lower GI bleeding: Epidemiology and diagnosis. Gastroenterology Clinics of North America 2005; 34 (4): 643-664.

4 Roberts S E, Button L A, Williams J G. Prognosis following upper gastrointestinal bleeding. PLOS ONE; December 2012; 7 (12).

5 Ahmed A, Ali L, Shehbaz L, Nasir S, Rizvi S R H, Aman $M Z$, et al. The prevalence of acute upper gastrointestinal bleeding and the factors causing hemorrhage as observed at a tertiary health care centre in Karachi, Pakistan. Pak J Surg 2017; 33 (1): 36-40.

6 Ismail F W, Mumtaz K, Shah H A, Hamid S, Abbas Z, Abid $S$, et al. Factors predicting in-hospital mortality in patients with cirrhosis hospitalized with gastroesophageal variceal hemorrhage. Indian Journal of Gastroenterology 2006; 25: 240-243.

7 Shah S M A, Mashia S A, Ghauri M A Y A, et al. Hepatic cirrhosis disease burden. Journal of Rawalpindi Medical College Students Supplement 2015; 19: 17-20. 
8 Shah S M A, Butt Z, Younis I, Afzal M, Atta H, Nadir A. Etiology of upper gastrointestinal bleed at Aziz Bhatti Shaheed Teaching Hospital Gujrat. Ann. Pak. Inst. Med. Sci 2016.

9 Manning-Dimmitt L L, Dimmitt S G, Wilson G R. Diagnosis of gastrointestinal bleeding in adults. Am Fam Physician 2005; 71: 1339-46.

10 Anand D, Gupta R, Dhar M, Ahuja V. Clinical and endoscopic profile of patients with upper gastrointestinal bleeding at tertiary care center of North India. Journal of Digestive Endoscopy 2014; 5 (4).

11 Colle I, Wilmer A, Le Moine O, Debruyne R, Delwaide J, Dhondt E, et al. Upper gastrointestinal tract bleeding management. Belgian guidelines for adults and children. Acta Gastroenterol Belg 2011; 74: 45-66.

12 Boåianu $A$ M, Matei $D$, Tanåãu $M$, Acalovschi $M$. Mortality and need of surgical treatment in acute upper gastrointestinal bleeding: A one year study in a tertiary center with a 24 hours / Day-7 Days / Week endoscopy call. Has Anything Changed? Chirurgia 2013; 108: 312-318.

13 Lahiff C, Shields W, Creåu I, Mahmud N, McKiernan S, Norris $S$, et al. Upper gastrointestinal bleeding: Predictors of risk in a mixed patient group including variceal and nonvariceal haemorrhage. European Journal of Gastroenterology and Hepatology 2012; 24: 149-154.

14 Saeed Z A, Ramirez F C, Hepps K S, Cole R A, Graham $D$ Y. Prospective validation of the Baylor bleeding score for predicting the likelihood of rebleeding after endoscopic hemostasis of peptic ulcers. Gastrointest Endosc 1995; 41: 561-565.

15 Vreeburg E M, Terwee C B, Snel P, Rauws E A, Bartelsman $\mathrm{J} \mathrm{F}$, Meulan $\mathrm{J} \mathrm{H}$, et al. Validation of the Rockall risk scoring system in upper gastrointestinal bleeding. BMJ 1999; 44: 331-335.

16 Wang C Y, Qin J, Wang J, Sun C Y, Cao T, Zhu D D. Rockall score in predicting outcomes of elderly patients with acute upper gastrointestinal bleeding. World J Gastroenterol 2013; 19: 3466-3472.

17 Rockall TA, Logan RF, Devlin HB, Northfield TC. Risk assessment after acute upper gastrointestinal haemorrhage. Gut 1996; 38: 316-21.

18 Hwang J H, Shergill A K, Acosta R D, Chandrasekhara V, Chathadi K V, Decker G A, et al. The role of endoscopy in the management of variceal hemorrhage. Gastrointestinal Endoscopy 2014; 80: 221-227.

19 Garber A, Albeldawi M, Mehta P P, Lopez R, Vargo J J, Jang S. Sa1676 Predicting in hospital mortality from non-variceal upper GI bleeding using a novel simple risk score. Gastrointestinal endoscopy 2014; 79: AB297-AB298.

20 Khan, J., Ali, M., Bakhsh Sobhi, H., Moazzam Waheed, S., Shahnawaz, I., Abdullah, M., et al. (2018) Etiology of upper GI bleeding on endoscopy. Neuroscience and Medicine, 9, 16-21. doi: 10.4236/nm.2018.91003.

21 Shah S M A, Butt Z, Younis I, Afzal M, Atta H, Nadir A. Etiology of upper gastrointestinal bleed at Aziz Bhatti Shaheed Teaching Hospital Gujrat. Ann. Pak. Inst. Med. Sci 2016: 80-84.

22 Lakhwani MN, Ismail AR, Barras CD, Tan WJ. Upper gastrointestinal bleeding in Kuala Lumpur Hospital, Malaysia. Med J Malaysia 2000; 55: 498-505.

23 Mahajan P, Chandail VS. Etiological and endoscopic profile of middle aged and elderly patients with upper gastrointestinal bleeding in a Tertiary Care Hospital in North India: A retrospective analysis. Journal of Midlife Health 2017; 8: 137-141.

24 Gregor H, Segal D, Rammal A, et al. A231 A randomized clinical trial to determine the efficacy of the biovac direct suction device during upper gastrointestinal bleeding: A feasibility analysis. Journal of the Canadian Association of Gastroenterology 2018; 1 : 403-404.

25 Czernichow P, Hochain P, Nousbaum JB, Raymond JM, Rudelli A, Dupas JL, et al. Epidemiology and course of acute upper gastro-intestinal haemorrhage in four French geographical areas. Eur J Gastroenterol Hepatol 2000; 12: 175-181.

26 Elghuel A. The characteristics of adults with upper gastrointestinal bleeding admitted to Tripoli Medical Center: a retrospective case-series analysis. Libyan J Med 2011; 6: 6283.

27 Elsebaey MA, Elashry $H$, Elbedewy TA, Elhadidy AA, Esheba NE, Ezat S, et al. Predictors of in-hospital mortality in a cohort of elderly Egyptian patients with acute upper gastrointestinal bleeding. Medicine 2018; 97: 16.

28 Shrestha U K, Sapkota S. Etiology and adverse outcome predictors of upper gastrointestinal bleeding in $\mathbf{5 8 9}$ patients in Nepal. Digestive Diseases and Sciences. 2014; 59: 814-822.

29 Mallick U K, Faruq M O, Ishaque S M, Areef Ahsan ASM, Fatema K, Ahmed F, et al. Early endoscopic findings in patients with upper gastrointestinal bleeding in Bangladesh. Bangladesh Crit Care J 2015; 3: 60-62. 
30 Lam K L Y, Wong J C T, Lau J Y W. Pharmacological treatment in upper gastrointestinal bleeding. Current Treatment Options in Gastroenterology 2015; 13: 369376.

31 Fujishiro $M$, Iguchi $M$, Kakushima N, Kato M, Sakata Y, Hoteya S, et al. Guidelines for endoscopic management of non $\square$ variceal upper gastrointestinal bleeding. Digestive Endoscopy 2016; 28: 363-378.

32 Rockall TA, Logan RF, Devlin HB, Northfield TC. Risk assessment after acute upper gastrointestinal haemorrhage. Gut 1996; 38: 316-21.
33 Bambha K, Kim WR, Pedersen R, et al. Predictors of early re-bleeding and mortality after acute variceal haemorrhage in patients with cirrhosis Gut 2008; 57 : 814-820.

34 Chaikitamnuaychok R, Patumanond J. Clinical risk characteristics of upper gastrointestinal hemorrhage severity: A multivariable risk analysis. Gastroenterol Res 2012; 5: 149-55.

35 Phang TS, Vornik V, Stubbs R. Risk assessment in upper gastrointestinal haemorrhage: Implications for resource utilization. N Z Med J 2000; 113: 331-3.

AUTHORSHIP AND CONTRIBUTION DECLARATION
\begin{tabular}{|c|l|l|}
\hline Sr. \# & \multicolumn{1}{|c|}{ Author(s) Full Name } & \multicolumn{1}{|c}{ Contribution to the paper } \\
\hline 1 & Naresh Kumar Seetlani & Conceived the idea. \\
2 & Khalid Imran & Reviewed the manuscirpt. \\
3 & Pooja Deepak & Writing of the manuscript. \\
4 & Fizza Tariq & Designed the Performa. \\
6 & Amanullah Abbasi & Edited the manuscript. \\
7 & Nadia Shams & Did the SPSS analysis. \\
8 & Tehseen Akhtar & Reviewed the manuscript.
\end{tabular}

